Review Article

\title{
Functional dyspepsia and the role of digestive enzymes supplement in its therapy
}

\author{
Onkar C. Swami*, Neel J. Shah
}

\author{
Medical Services, Unichem \\ Laboratories Limited, Mumbai, \\ Maharashtra, India \\ Received: 24 February 2017 \\ Accepted: 28 March 2017 \\ *Correspondence to: \\ Dr. Onkar C. Swami, \\ Email: \\ onkar.swami@unichemlabs.com \\ Copyright: (C) the author(s), \\ publisher and licensee Medip \\ Academy. This is an open- \\ access article distributed under \\ the terms of the Creative \\ Commons Attribution Non- \\ Commercial License, which \\ permits unrestricted non- \\ commercial use, distribution, \\ and reproduction in any \\ medium, provided the original \\ work is properly cited
}

\begin{abstract}
Functional dyspepsia represents a heterogeneous group of gastrointestinal disorders marked by the presence of upper abdominal pain or discomfort. Reported prevalence of dyspepsia in the world varies from 11-30\%. Basic Pathophysiology of functional dyspeptic symptoms is unclear and is considered to occur due to a combination of visceral hypersensitivity, gastric motor dysfunction and psychological factors. Strategies such as acid suppression, prokinetics and $H$. pylori eradication have been used with some success. Transient deficiency in digestive enzymes is one of the contributors for functional dyspepsia. The primary digestive enzymes are proteases, amylases and lipases. A commonly used therapeutic approach in its treatment is the use of oral enzymes supplementation therapy. Commercially, digestive enzymes are obtained from plant, animal and microbial sources. This review summarizes the pathophysiology of functional dyspepsia, different pharmacological approaches and focuses on the safety and efficacy of digestive enzymes in managing dyspepsia. Keywords including functional dyspepsia, digestive enzymes, lipase, diastase, papain, pepsin, trypsin and chymotrypsin were searched in databases such as Google, Google Scholar, PubMed, pharmacopoeia and textbooks.
\end{abstract}

Keywords: Amylase, Functional dyspepsia, Lipase, Oral digestive enzymes supplement, Pepsin

\section{INTRODUCTION}

Dyspepsia can be defined as 'a symptom or set of symptoms that most physicians consider originating from the gastroduodenal area'. ${ }^{1}$ The symptom complex may be caused by peptic ulcer disease, gastro-esophageal reflux, or gastric cancer but is most often due to non-ulcer dyspepsia. Numerous studies have reported that majority of dyspepsia cases have minor abnormalities of uncertain significance or an entirely normal endoscopy, and are labeled as having functional dyspepsia or non-ulcer dyspepsia. $^{2}$

Functional dyspepsia is the commonest cause of dyspeptic symptoms across the globe, accounting for more than $70 \%$ of the cases of dyspepsia. ${ }^{2}$ Functional dyspepsia can be defined as 'Persistent or recurrent pain or discomfort centered in the upper abdomen; evidence of organic disease likely to explain the symptoms is absent, including at upper endoscopy'.3 For categorizing as functional, further, the symptoms must have begun 6 months prior to diagnosis and be active for 3 months. ${ }^{4}$ People with functional dyspepsia have a significantly reduced quality of life when compared to general population. Depending on definitions used, the global prevalence of functional dyspepsia varies from 11-30\%, and Indian prevalence is $30.4 \% .^{5}$

ROME-III criteria have classified functional gastrointestinal (GI) disorders for adults according to site: esophageal, gastroduodenal, bowel, abdominal pain, gall bladder and anorectal disorders. For pediatrics, functional GI disorders are classified according to age. Functional gastroduodenal disorders are further classified as functional dyspepsia, belching disorders, nausea and vomiting disorders and rumination syndrome. ${ }^{4}$ Functional dyspepsia is of two types: postprandial distress and epigastric pain syndromes. Postprandial distress represents a dysmotility-like syndrome where there is early satiety and epigastric pain type represents a 
syndrome where there is burning, ulcer like pain. ${ }^{2}$ However, there is considerable overlap with almost $35 \%$ patients of functional dyspepsia experiencing both symptoms. ${ }^{6}$ A study associated some common risk factors with functional dyspepsia and found the following association: female gender (Odds: 2.01), consumption of betel nuts (Odds: 4.55), non-steroidal anti-inflammatory drugs (Odds: 6.60), anxiety (Odds: 3.41), concomitant Irritable Bowel Syndrome (IBS) (Odds: 6.89), H. pylori (Odds: 1.86), unmarried status (Odds: 4.22), sleep disturbance (Odds: 2.56) and depression (Odds: 2.34$){ }^{6}$

\section{METHODS}

The materials for this review were obtained from an extensive search using electronic databases which included PubMed, Google Scholar and Google. Articles were searched till November 2016. Literature on functional dyspepsia; its classification, management and digestive enzymes was retrieved. The key words used for the literature search included functional dyspepsia, digestive enzymes, lipase, diastase, papain, pepsin, trypsin, and chymotrypsin. The search included research articles, reviews, meta-analyses and textbooks including pharmacopoeias. Articles found in foreign languages were translated with help of certified translators. Since this article focuses on a broad area, a systematic review could not be performed.

\section{Pathophysiology of functional dyspepsia}

The proposed pathophysiologic mechanisms associated with functional dyspepsia include genetic susceptibility, delayed as well as accelerated gastric emptying, visceral hypersensitivity to acid or mechanical distention, impaired gastric accommodation, abnormal fundic phasic contractions, abnormal antroduodenal motility, acute and chronic infections, and psychosocial co-morbidity. ${ }^{2}$ Transient deficiency in digestive enzyme is also a contributor for functional dyspepsia. Yet the exact pathophysiological mechanisms that cause symptoms in an individual patient remain difficult to delineate. ${ }^{7}$ Epidemiologic studies reported that, there is an association between functional dyspepsia and psychological disorders. Symptoms of neurosis, anxiety, hypochondriasis, and depression are more common in patients being evaluated for unexplained gastrointestinal complaints than in healthy controls. ${ }^{4}$

\section{Treatment of functional dyspepsia}

\section{Placebo}

The rate of response with placebo was found to be as high as $50 \%$ in a study on functional GI disorders in children and adolescents. ${ }^{8}$ This highlights the involvement of the central nervous system in functional disorders and the role of reassurance which many physicians practice in these conditions.

\section{Acid-suppression therapy}

Employing acid suppressing agents is logical as there is evidence that there is impaired duodenal clearance and increased duodenal sensitivity to acid (exogenously administered) in dyspeptic patients. ${ }^{9}$ A comparison of antacids with digestive enzymes has been summarized in Table 1.

Table 1: Advantages of digestive enzymes preparation over antacids.

\begin{tabular}{|c|c|}
\hline Antacid & Digestive enzymes preparation \\
\hline Does not aid digestion but reduces it & Increases digestive power \\
\hline Unnatural & Matches the natural metabolism \\
\hline Provides temporary relief & Lasting solution for GI problems \\
\hline Some disturb the synthesis of gastric acid & Does not interfere with the internal metabolism \\
\hline Blocks the absorption of nutrients and drugs & Helps in complete absorption of nutrients \\
\hline Decreased the anti-microbial activity of stomach & Promotes the anti-microbial activity of stomach \\
\hline $\begin{array}{l}\text { Calcium base leads to several disorders like renal failure, } \\
\text { hypercalcemia and alkalosis }\end{array}$ & Calcium not present \\
\hline $\begin{array}{l}\text { Side-effects include constipation, dizziness, loss of appetite, } \\
\text { unpleasant taste, nausea, increased thirst }\end{array}$ & Well tolerated with minimum side effects \\
\hline
\end{tabular}

\section{Prokinetic agents}

These can accelerate gastric emptying and enhance gastric accommodation. Examples include cisapride, mosapride and metoclopramide. Older agents like cisapride are no longer preferred due to their QT prolongation adverse effect. A new agent, acotiamide has been tested in functional dyspepsia and was found to benefit both the above-mentioned parameters based on real time ultrasonography findings. ${ }^{10}$ Postprandial fullness, upper abdominal bloating and early satiation were also reduced by acotiamide. ${ }^{11}$

\section{H. pylori eradication}

A meta-analysis found that H. pylori eradication led to symptom relief and reduced the development of peptic ulcers. On the other hand, it did not improve the quality 
of life of patients with functional dyspepsia and led to adverse events. $^{12}$

Other agents including antidepressants and psychological therapy have also been tried. A comparison of some of the agents for the treatment of functional dyspepsia has been summarized in Table 2 .

\section{Table 2: Comparison of different therapies for the treatment of functional dyspepsia.}

\begin{tabular}{|c|c|}
\hline Therapy & $\begin{array}{l}\text { Relative risk reduction compared to } \\
\text { placebo }\end{array}$ \\
\hline Prokinetics & $33 \%$ (95\% CI: $18 \%$ to $45 \%)$ \\
\hline $\mathrm{H}_{2}$ blockers & $23 \%$ (95\% CI: $8 \%$ to $35 \%)$ \\
\hline $\begin{array}{l}\text { Proton pump } \\
\text { inhibitors }\end{array}$ & $13 \%$ (95\% CI: $4 \%$ to $20 \%)$ \\
\hline $\begin{array}{l}\text { Bismuth } \\
\text { salts }\end{array}$ & $40 \%$ (Marginally: $95 \%$ CI: -3 to $65 \%$ ) \\
\hline Antacids & \multirow{2}{*}{ No statistical difference } \\
\hline Sucralfate & \\
\hline
\end{tabular}

Due to multifactorial pathogenesis of functional dyspepsia no single drug is suitable for all patients. As a consequence, different categories of drugs described above have all been tried in different groups of patients with no single agent emerging as the drug of choice. Hence, there exists an unmet need in the treatment of dyspepsia.

\section{Oral digestive enzymes for treating dyspepsia}

\section{Digestive enzymes inadequacy or deficiency}

Digestive enzymes are often prescribed to patients with various dyspeptic complaints. Reports suggested a beneficial role of enzyme preparations in dyspepsia. ${ }^{13}$ In addition to consuming adequate levels of raw foods, a common approach to supporting the patient with digestive enzyme inadequacy is oral enzyme replacement. A study pointed the role of pancreatic enzyme supplementation in functional dyspepsia where the therapy significantly reduced the symptoms of flatulence, bloating, belching, fullness and post-prandial distress. ${ }^{14}$

The rational for prescription of digestive enzymes is that carbohydrates, proteins and fats are initially converted to smaller units by various digestive enzymes and are then assimilated.

By aiding the digestive process, the dyspeptic symptoms would be ameliorated. Hence, to assist the adequate digestion of every nutrient, a combination of different enzymes must be supplemented.

Table 3: Causes of enzyme inadequacy or deficiency.

\begin{tabular}{|ll|}
\hline Factors & \\
\hline $\begin{array}{l}\text { Impaired } \\
\text { secretion }\end{array}$ & Dysfunction of digestive organs, mucosal disease, gastrointestinal surgery and nutritional deficiency \\
\hline Habits & Poor eating habits (inadequate chewing of food) "eating on the run," or eating late in the day. \\
\hline $\begin{array}{l}\text { Dietary } \\
\text { choices }\end{array}$ & $\begin{array}{l}\text { Certain dietary choices, such as excessive consumption of alcohol, refined carbohydrates and fat, as well as } \\
\text { a high meat and cooked food diets with few raw, enzyme-rich foods. }\end{array}$ \\
\hline Age & Aging alters digestive enzyme secretion with linear decrease reported after $4^{\text {th }}$ decade of life. \\
\hline
\end{tabular}

Several factors cause enzyme inadequacy and deficiency, some of which are enumerated in Table $3 .{ }^{15}$ Aging leads to decrease in both basal and stimulated pepsin output. In elderly, pepsin output is reduced by approximately $40 \% .{ }^{16}$ In a study on pancreatic secretion in the elderly, it was found that the concentrations of lipase, phospholipase and chymotrypsin decreased linearly from the $3^{\text {rd }}$ decade onwards. ${ }^{15}$ It is fairly common for elderly individuals to experience both a decrease in hydrochloric acid production as well as a general decline in digestive enzyme secretion. ${ }^{16}$ With a growing elderly population, unhealthy diets and stressful life styles, it is likely that healthcare professionals will find more and more patients developing digestive problems.

It is estimated that $58 \%$ of the population suffers from some type of digestive disorder. A lack of optimal digestive function associated with enzyme inadequacy may lead to malabsorption and a host of related conditions.

\section{Role of primary digestive enzymes}

Amylase is the most important enzyme for digestion of carbohydrates. Amylase is a glycoside hydrolase and acts on $\alpha$-1, 4-glycosidic bonds of polysaccharides (starch and glycogen) and degrades them into dextrins, disaccharides (maltose) and monosaccharides (glucose). Amylases are classified into endoamylase and exoamylase according to the manner in which the glycosidic bond is attacked. Endoamylases attack the $\alpha$-1, 4-glycosidic linkage at random while exoamylase hits from the non-reducing outer polysaccharide chain ends. ${ }^{17}$

$\alpha$-amylase is a kind of endoamylase that rapidly hydrolyzes $\alpha-1,4$ glycosidic linkage present in gelatinized starch, amylase and pullulan to produce soluble dextrin, 
some maltose, and glucose. ${ }^{13}$ It is a type of endoamylase present in human saliva and pancreatic secretion and can be exogenously isolated from Bacillus subtilis, Aspergillus oryzae, and barley malt. $\beta$-amylase and glucoamylase are of vegetable or microbial origin. $\beta$ amylase yields $\beta$-limit dextrins and maltose, and glucoamylase yield glucose. Amylase from a variety of sources is being used as an ingredient of preparations of mixed digestive enzymes. ${ }^{17}$

Fungal Diastase (diastase is another name for amylase) is derived from a fungus, Aspergillus oryzae and contains high activity of enzyme $\alpha$-amylase. In saccharification, fungal source $\alpha$-amylase has higher efficiency compared to bacterial enzyme. ${ }^{18}$ Fungal diastase digests granular starch in coordination with mucosal $\alpha$-glucosidases. ${ }^{19}$ Its starch digesting capacity is convincingly good over wide range of $\mathrm{pH}$ with maximum activity at $\mathrm{pH}$ 5. Further, diastase can get reactivated in intestine after it leaves acidic environment of stomach. The reaction velocity for dextrinising starch molecule by fungal diastase is very rapid. It is common constituent of mixed digestive enzymes for treatment of indigestion. ${ }^{13}$

Pepsin is one of the three main proteolytic enzymes in the digestive system, the other two being chymotrypsin and trypsin. Pepsinogen is a pro-form zymogen of pepsin. It is released in the stomach by chief cells. This zymogen is activated by hydrochloric acid released from parietal cells in the stomach linings. Gastrin is the hormone that triggers the release of pepsinogen and also controls the secretion of hydrochloric acid from the stomach lining once food is ingested. ${ }^{20}$

Pepsin's function is to break down proteins into smaller pieces called polypeptides. Pepsin breaks proteins only at certain points so that the protein is not digested completely to the amino acid level. For this effect, the food needs to pass to the intestines where other enzymes complete the digestion process. Pepsin functions in acidic environment with $\mathrm{pH}$ of 1.5 to 2 and gets denatured if the $\mathrm{pH}$ is more than 5.0. Pepsin needs optimum temperature of range $37^{\circ} \mathrm{C}$ to $42^{\circ} \mathrm{C} .{ }^{20}$

Commercially, pepsin is prepared from gastric mucosa of pigs, cattle or sheep. It contains proteinases which are active at a $\mathrm{pH}$ of $1-5$. Pepsin is most proficient in cleaving bonds involving the aromatic amino acids, phenylalanine, tryptophan, and tyrosine. Pepsin has been regularly used as an adjunct in the treatment of gastric hypochlorhydria, in dyspepsia and to treat deficiencies of digestive enzyme secretion. ${ }^{20}$

Trypsin is a proteolytic enzyme obtained by the activation of trypsinogen extracted from mammalian pancreas. Crystallized trypsin is obtained from extract of the pancreas of healthy bovine or porcine animals, or both. It is used in mixture with other enzyme in treatment of gastrointestinal disorder. Furthermore, it is used locally in debridement of wounds and orally with chymotrypsin for treatment of inflammation. ${ }^{21}$ Chymotrypsin is another proteolytic enzyme produced by pancreas. It is selective for peptide bonds with aromatic or large hydrophobic side chains on the carboxyl side of this bond. In addition, chymotrypsin catalyzes the hydrolysis of ester bonds. Along with other proteolytic enzyme it helps in digestion of proteins. It is used in management of inflammation and as a multienzyme supplement in digestive disorder. ${ }^{22}$

Papain is a non-specific proteolytic enzyme obtained from latex of the fruit of the papaya tree (Carica papaya). It requires the presence of sulfhydryl groups (eg, cysteine) to stimulate activity. ${ }^{23}$ Hence, is classified under cysteine protease. It has been used in wound debridement. ${ }^{23}$ An interesting use is in the emergency department for resolving esophageal meat impaction. ${ }^{24}$

Lipase (triacylglycerol acylhydrolases) catalyzes the partial or complete hydrolysis of triacylglycerols. Lingual, pancreatic and enteric lipases are involved in complete digestion of lipids. They hydrolyze ester bond of triglycerides into free fatty acid and glycerol. They are commonly used in enzyme supplementation for treatment of digestive disorder of lipids. ${ }^{25}$

Lipases can be produced by all biological systems, viz. animals, plants and microorganisms. However, microbial lipases are receiving more attention because of a variety of catalytic activities, high yields, ease of genetic manipulation, regular supply due to absence of seasonal fluctuations, rapid growth of microorganisms on inexpensive media, greater stability than the corresponding plant and animal enzymes and since their production is more convenient and safer. ${ }^{26}$ Lipase produced by $\mathrm{C}$. cylindracea has been one of the most widely used enzymes due to its high activity in hydrolytic reactions. ${ }^{27} \mathrm{~A}$ study on 16 healthy volunteers reported improvement of post-prandial fullness after ingestion of a fatty meal. ${ }^{28}$

Other digestive enzymes which aid in digestion of macromolecules are lactase, alpha galactosidase, cellulase, beta glucanase, invertase and peptidase.

\section{Clinical evidence of efficacy and safety of oral enzymes supplement}

Banka et al., evaluated the efficacy and safety of fungal diastase and papain in patients $(n=100)$ of non-ulcer dyspepsia. Efficacy and tolerability were assessed at baseline, at day 7 and at day 14 of treatment. Significant improvement in frequency and severity of all symptoms of indigestion (fullness, belching, bloating, flatulence and postprandial distress) was noted at day 14 of treatment compared to baseline (Table 4). Total $67 \%$ and $29 \%$ of physicians rated excellent and good efficacy, respectively, in resolving dyspeptic symptoms. Similarly, $65 \%$ and $27 \%$ of patients rated excellent and good tolerability, respectively. The combination was well 
tolerated with minor adverse effects (nausea and skin problems). ${ }^{13}$

Table 4: Mean change in severity of indigestion symptoms score.

\begin{tabular}{|llll|}
\hline Symptom & Baseline & Day 7 & Day 14 \\
\hline Fullness & 0.60 & $0.19^{*}$ & $0.06^{*}$ \\
\hline Belching & 1.20 & $0.67^{*}$ & $0.40^{*}$ \\
\hline Bloating & 1.20 & $0.30^{*}$ & $0.08^{*}$ \\
\hline Flatulence & 1.10 & $0.40^{*}$ & $0.04^{*}$ \\
\hline Postprandial distress & 0.30 & $0.04^{*}$ & 0.04 \\
\hline
\end{tabular}

$(* \mathrm{P}<0.05$ : Significant; Severity Score: $0=$ Mild; $1=$ Moderate; $2=$ Severe $)$. Data adopted from Banka et al

A post-marketing surveillance study was conducted to evaluate the efficacy and tolerability of a multienzyme preparation containing amylase, protease, lipase, lactase and alpha-galactosidase. ${ }^{14}$ The FDC was given for 14 day. Treatment was associated with a significant reduction in frequency and severity of every abdominal symptom (flatulence, bloating, belching, dyspepsia, feeling of fullness, abdominal discomfort, heart burn and anorexia) ( $p<0.0001)$. In the overall assessment by physicians $55 \%$ rated the preparation as excellent and $41 \%$ as good. Assessment by patients in terms of tolerability and effectiveness was also carried out with $51 \%$ rated the preparation as excellent and $44 \%$ rated it as good.

Deyneko NF et al., assessed the efficacy and safety for the Fixed Dose Combination (FDC) of Fungal diastase, papain, nicotinamide and simethicone in 68 patients of intestinal indigestion. Among them 23 patients had chronic pancreatitis (leading to insufficient function), 30 had chronic non-ulcer colitis, 10 had initial stages of hepatic cirrhosis, and 5 had cholelithiasis. Patients received 2 pills of study drug twice a day for first 5 days followed by 1 pill thrice a day for 10-12 days. The FDC was well tolerated and no side effect was reported. Post treatment flatulence and pain was completely eliminated in patients with chronic pancreatitis and colitis. Additionally, defecation was normalized and borborygmus was eliminated. ${ }^{29}$

Meteorism is a symptom that refers to a swollen abdomen, generated by the increase in the amount of intestinal gas, exerting more pressure than usual inside the digestive system, causing various discomforts, especially more or less intense pain and flatulence to eliminate the gas. Beryozov VM et al., evaluated efficacy and safety of FDC of fungal diastase, papain, activated carbon, simethicone and nicotinamide in treatment of patients with meteorism $(n=118)$ in comparison with carboenterosorbent. Among them 31 patients had hepatic cirrhosis, 36 patients had chronic pancreatitis, 35 patients had IBS and 16 patients had non-specific ulcerative colitis. The FDC group $(n=57)$ received one pill with every meal and carboenterosorbent group received 1.5 gm/day before every meal. After 10 days of treatment, there was a significant increase in ultrasound availability ratio (an ultrasound method of evaluating meteorism activity intensity based on visualization of internal organs) and decrease in pain index $(\mathrm{P}<0.05)$, with the FDC of fungal diastase, papain, activated carbon, simethicone and nicotinamide compared to carboenterosorbent group. ${ }^{30}$

Ran et al. assessed patients ( $n=151,18$ to 75 years) diagnosed with chronic digestive diseases presenting with two or more dyspepsia symptoms such as epigastric pain, abdominal distension, epigastric burn, belching, diarrhea and constipation. The efficacy of an enzyme preparation containing 24-mg enzyme extract of Aspergillus oryzae (cellulase, protease and amylase) and $220 \mathrm{mg}$ pancreatin (lipase, proteinase and amylase) given post-meal (2 tablets), thrice a day was assessed in these patients. Patients recruited included functional dyspepsia, GERD, a peptic ulcer (without complications such as bleeding, perforation, stenosis and malignancy), chronic gastritis, partial gastrectomy, small or large intestinal resection, diverticulosis, liver cirrhosis (without serious complications), chronic biliary disease including cholecystitis, cholelithiasis, polyps of the gallbladder, cholecystectomy, chronic pancreatic disease including chronic pancreatitis, chronic pancreatic insufficiency, diabetes mellitus with dyspepsia symptoms and geriatric reduction of digestive function. Compared with placebo, 2 weeks of enzymatic treatment decreased the severity index of dyspepsia symptoms significantly. The efficacy rates of enzyme preparation and the placebo on dyspepsia were $90 \%$ and $22 \%$, respectively $(\mathrm{P}<0.01) .{ }^{31}$

\section{SUMMARY}

Functional dyspepsia is a commonly encountered complaint arising due to a variety of causes, not clearly understood. Drugs targeting different pathologies including acid suppression, H. Pylori eradication, prokinetics, anti-flatulents and anti-depressants have been tried. Digestive enzyme combinations have been in use since a long time and have a modest response in ameliorating various symptoms of dyspepsia due to both functional and organic causes. Amylase, pepsin and lipase are the main enzymes involved in digestion of carbohydrates, proteins and fats, respectively. They are widely available in combination with other digestive enzymes across the world and are safe and devoid of serious adverse effects.

\section{Funding: No funding sources \\ Conflict of interest: None declared \\ Ethical approval: Not required}

\section{REFERENCES}

1. Mearin F, Calleja JL. Defining functional dyspepsia. Rev Esp Enferm Dig. 2011;103(12):640-7.

2. Talley NJ, Ford AC. Functional Dyspepsia. N Engl J Med. 2015;373(19):1853-63. 
3. Talley N, Stanghellini V, Heading R, Koch K, Malagelada J, Tytgat G. Functional gastroduodenal disorders. Gut. 1999;45(2):1137-42.

4. Drossman DA. The Functional Gastrointestinal Disorders and the Rome III Process. Gastroenterology. 2006;130(5):1377-90.

5. Mahadeva S, Goh KL. Epidemiology of functional dyspepsia: A global perspective. World J Gastroenterol. 2006;12(17):2661-6.

6. Fang YJ, Liou JM, Chen CC, Lee JY, Hsu YC, Chen MJ. Distinct aetiopathogenesis in subgroups of functional dyspepsia according to the Rome III criteria. Gut. 2015;64(10):1517-28.

7. Choung RS, Talley NJ. Novel mechanisms in functional dyspepsia. World J Gastroenterol. 2006; 12(5):673-7.

8. Kaminski A, Kamper A, Thaler K, Chapman A, Gartlehner G. Antidepressants for the treatment of abdominal pain-related functional gastrointestinal disorders in children and adolescents. [Internet]. In: Cochrane Database of Systematic Reviews. John Wiley and Sons, Ltd; 2011.

9. Samsom M, Verhagen MA, VanBerge H, Smout AJ. Abnormal clearance of exogenous acid and increased acid sensitivity of the proximal duodenum in dyspeptic patients. Gastroenterology. 1999;116(3):515-20.

10. Kusunoki H, Haruma K, Manabe N, Imamura H, Kamada T, Shiotani A, et al. Therapeutic efficacy of acotiamide in patients with functional dyspepsia based on enhanced postprandial gastric accommodation and emptying: randomized controlled study evaluation by real-time ultrasonography. Neurogastroenterol Motil. 2012;24(6):540-5.

11. Matsueda K, Hongo M, Tack J, Saito Y, Kato H. A placebo-controlled trial of acotiamide for mealrelated symptoms of functional dyspepsia. Gut. 2012;61(6):821-8.

12. Du LJ, Chen BR, Kim JJ, Shen JH, Dai N. Helicobacter pylori eradication therapy for functional dyspepsia: Systematic review and meta-analysis. World J Gastroenterol. 2016;22(12):3486-95.

13. Banka N, Sawant P, Vartak M, Pawar D. Efficacy and Tolerability of Unienzyme MPS- A Multienzyme Preparation with Simethicone in Patients with Nonulcer ,Dyspepsia. Indian Medical Gazette. 2001;135(7):294-305.

14. Khandke DA, Shirsath PA, Jain SK. Post-Marketing Surveillance Study to Assess the Efficacy and Tolerability of Al5zyme-A Multienzyme Preparation in Patients with Functional Dyspepsia. Indian Medical Gazette. 2013;181-91.

15. Laugier R, Bernard JP, Berthezene P, Dupuy P. Changes in pancreatic exocrine secretion with age: pancreatic exocrine secretion does decrease in the elderly. Digestion. 1991;50(3-4):202-11.

16. Feldman M, Cryer B, McArthur K, Huet BA, Lee E. Effects of aging and gastritis on gastric acid and pepsin secretion in humans: a prospective study. Gastroenterology. 1996;110(4):1043-52.

17. Sweetman S. Eds. Martindale; Amylase In: The Complete Drug reference. The Pharmaceutical Press: London; 2009:2256.

18. Sivaramakrishnan S, Gangadharan D, Nampoothiri KM, Soccol CR, Pandey A. Alpha amylase production by Aspergillus oryzae employing solidstate fermentation. JSIR. 2007;668.

19. Dhital S, Lin AH-M, Hamaker BR, Gidley MJ, Muniandy A. Mammalian Mucosal $\alpha$-Glucosidases Coordinate with $\alpha$-Amylase in the Initial Starch Hydrolysis Stage to Have a Role in Starch Digestion beyond Glucogenesis. PLoS ONE. 2013;8(4).

20. Pepsin. In: Sweetman S. Eds. Martindale, The Complete Drug reference. The Pharmaceutical Press: London; 2009:2362.

21. Trypsin. In: Sweetman S. Eds. Martindale, The Complete Drug reference. The Pharmaceutical Press: London; 2009:2362.

22. Chymotrypsin. In: Sweetman S. Eds. Martindale, The Complete Drug reference. The Pharmaceutical Press: London; 2009:2362.

23. Smith RG. Enzymatic debriding agents: an evaluation of the medical literature. Ostomy Wound Manage 2008;54(8):16-34.

24. Lee J, Anderson R. Proteolytic enzymes for oesophageal meat impaction. Emerg Med J. 2005; 22(2):122-3.

25. Lipase. In: Sweetman S. Eds. Martindale, The Complete Drug reference. The Pharmaceutical Press: London; 2009:2362.

26. Hasan F, Shah AA, Hameed A. Industrial applications of microbial lipases. Enzyme Microb Technol 2006;39(2):235-51.

27. Salihu A, Alam MZ, Abdul Kalim MI, Salleh HM. Characterization of Candida cylindracea lipase produced from Palm oil mill effluent based medium. IJCBS. 2012;2:24-31.

28. Levine ME, Koch SY, Koch KL. Lipase Supplementation before a High-Fat Meal Reduces Perceptions of Fullness in Healthy Subjects. Gut Liver. 2015;9(4):464-9.

29. Deyneko N, Sirodza O, Voytsekhova L, Usenko L, Skalozub T, Usenko V. Use Of "Unienzymewith Mps" In the Complex Treatment of Chronic Diseases of Digestive System] Use Of "Unienzyme With Mps" In The Integrated Treatment Of Chronic Diseases Of Digestive Bodies. Use Of "Unienzymewith Mps" In Complex Treatment Of Chronic Diseases Of Digestive System]. Modern gastroenterology, Modern Gastroenterology 2005;5 (25):66-8.

30. Beryozov V, Rudenko N, Nechipurenko T, Dorofeev A, Tomash O, Andrienko I, et al. The Possibilities of The Differentiated Approach to Treatment of Patients with Meteorism, Possibilities of the differential approach to treatment of patients with meteorism. Modern gastroenterology, Modern Gastroenterology. 2005;3(23):76-7. 
31. Ran Z, Yuan Y, Li Z. The efficacy of Combizym in the treatment of Chinese patients with dyspepsia: a multicenter, randomized, placebo-controlled and cross-over study. J Dig Dis. 2009;10(1):41-8.
Cite this article as: Swami OC, Shah NJ. Functional dyspepsia and the role of digestive enzymes supplement in its therapy. Int J Basic Clin Pharmacol 2017;6:1035-41. 